RESEARCH

\title{
Initial response of young people with thyrotoxicosis to block and replace or dose titration thionamide
}

\author{
Claire L Wood1,2, Niamh Morrison', Michael Cole3, Malcolm Donaldson4, David B Dunger5,6, Ruth Wood7, \\ Simon H S Pearce 2,8 and Timothy D Cheetham ${ }^{1,2}$ on behalf of the British Society for Paediatric Endocrinology \\ and Diabetes (BSPED)
}

\author{
1Department of Paediatric Endocrinology, Great North Children's Hospital, Royal Victoria Infirmary, Newcastle-upon-Tyne, UK \\ 2Translational and Clinical Research Institute, Faculty of Medical Sciences, Newcastle University, International Centre for Life, Central Parkway, Newcastle \\ upon Tyne, UK \\ 3Population Health Sciences Institute, Newcastle University, Baddiley-Clark Building, Newcastle upon Tyne, UK \\ ${ }^{4}$ Department of Child Health, University of Glasgow School of Medicine, Glasgow, UK \\ ${ }^{5}$ Department of Paediatrics, University of Cambridge, Cambridge Biomedical Campus, Cambridge, UK \\ ${ }^{6}$ Wellcome Trust-MRC Institute of Metabolic Sciences, University of Cambridge, Cambridge, UK \\ ${ }^{7}$ Newcastle Clinical Trials Unit, Newcastle University, Newcastle upon Tyne, UK \\ ${ }^{8}$ Department of Endocrinology, Royal Victoria Infirmary, Newcastle-upon-Tyne, UK
}

Correspondence should be addressed to T Cheetham: tim.cheetham@nhs.net

\begin{abstract}
Objective: Patients with thyrotoxicosis are treated with anti-thyroid drug (ATD) using block and replace (BR) or a smaller, titrated dose of ATD (dose titration, DT).

Design: A multi-centre, phase III, open-label trial of newly diagnosed paediatric

thyrotoxicosis patients randomised to BR/DT. We compared the biochemical response to BR/DT in the first 6 months of therapy.

Methods: Patients commenced $0.75 \mathrm{mg} / \mathrm{kg}$ carbimazole (CBZ) daily with randomisation to BR/DT. We examined baseline patient characteristics, CBZ dose, time to serum thyroidstimulating hormone (TSH)/free thyroxine (FT4) normalisation and BMI Z-score change. Results: There were 80 patients (baseline) and 78 patients ( 61 female) at 6 months. Mean CBZ dose was $0.9 \mathrm{mg} / \mathrm{kg} /$ day (BR) and $0.5 \mathrm{mg} / \mathrm{kg} /$ day (DT). There was no difference in time to non-suppressed TSH concentration; 16 of 39 patients (BR) and 11 of 39 (DT) had suppressed TSH at 6 months. Patients with suppressed TSH had higher mean baseline FT4 levels (72.7 vs 51.7 pmol/L; $95 \% \mathrm{Cl}$ for difference $1.73,31.7 ; P=0.029$ ). Time to normalise FT4 levels was reduced in DT (log-rank test, $P=0.049$ ) with $50 \%$ attaining normal FT4 at 28 days $(95 \% \mathrm{Cl} 25,32)$ vs 35 days in BR $(95 \% \mathrm{Cl} 28,58)$. Mean BMI Z-score increased from 0.10 to 0.81 at 6 months $(95 \% \mathrm{Cl}$ for difference $0.57,0.86 ; P<0.001)$ and was greatest in patients with higher baseline FT4 concentrations.

Conclusions: DT-treated patients normalised FT4 concentrations more quickly than BR. Overall, 94\% of patients have normal FT4 levels after 6 months, but 33\% still have TSH suppression. Excessive weight gain occurs with both BR and DT therapy.
\end{abstract}




\section{Introduction}

Thyrotoxicosis affects around 100 children under the age of 15 years in the UK every year (1) although the incidence may be increasing (2). Management typically involves the administration of thionamide anti-thyroid drug (ATD) with the aim of normalising thyroid hormone levels and then maintaining the patient in a euthyroid state. The ATD chosen in the UK is usually carbimazole (CBZ) because of the significant risk of liver dysfunction with propylthiouracil. ATD can be administered in a dose intended to prevent endogenous thyroid function, with thyroxine replacement added before the patient becomes hypothyroid. This approach is called block and replace (BR). An alternative approach is to gradually reduce the dose of ATD and then adjust the dose to maintain a euthyroid state. This approach is called dose titration (DT). Both ATD strategies are used in the UK and elsewhere (3). Detailed information about the initial response to ATD using the two different regimens (BR and DT) is lacking, and this could help clinicians and families to decide which strategy to use. This is important because there is little difference in terms of longer-term biochemical control (3), and other components of patient response to ATD have attracted interest recently including the risk of overweight and obesity $(4,5,6)$. We have recently reported the outcome of a prospective, multicentre phase III, un-blinded randomised trial comparing BR and DT ATD treatment in 80 young patients with thyrotoxicosis (7). This publication reflected the primary trial outcome which was biochemical control beyond the first 6 months after diagnosis. In this paper, we describe an analysis of the initial, first 6 months response to ATD in BR and DT groups which had not been conducted when the primary trial outcome was published. Whilst there was no difference in biochemical control beyond 6 months, our hypothesis was that patients randomised to BR would become biochemically euthyroid more quickly because of a tendency for them to receive a larger initial ATD dose.

\section{Materials and methods}

\section{Background to data collection}

We analysed the data from a prospective, multi-centre phase III, un-blinded randomised trial comparing BR and DT ATD treatment in 80 young patients with thyrotoxicosis (7). The original trial was designed to determine whether there was any difference in biochemical control between the BR and DT groups beyond 6 months. In this article, we present data from the first 6 months post-diagnosis. We describe the detailed baseline characteristics of the cohort including the frequency of eye signs linked to thyrotoxicosis as well as initial change in BMI on ATD. We also examined the early serum thyroid-stimulating hormone (TSH) and free thyroxine (FT4) response in the two groups; specifically the time taken for TSH levels to rise or for FT4 concentrations to fall within the local reference ranges. Free tri-iodothyroinine (FT3) concentrations were not measured routinely in this trial.

\section{Participants}

Participants were UK-based patients diagnosed with thyrotoxicosis between the ages of 2 and 16 years and recruited at 15 centres. Patients presented with a suppressed serum TSH (low levels that were below the assay threshold according to the local reference range) and raised thyroid hormone concentrations (above the local reference range). Patients with toxic thyroid nodules, McCune Albright syndrome or previous episodes of thyrotoxicosis were excluded.

\section{Randomisation}

Details about randomisation have been published (7). Briefly, patients were allocated to the BR and DT treatment groups in the ratio 1:1 according to four stratification factors which were age $(<10$ or $\geq 10$ years), FT4 level at presentation $(<50 \mathrm{pmol} / \mathrm{L}$ or $\geq 50 \mathrm{pmol} / \mathrm{L}$ ), sex (male or female) and geographical region (Anglia, Midlands, NorthEast, North-West, South-East, Scotland, Wales, Yorkshire). Patients were recruited at Aberdeen (3 participants), Birmingham (9), Cambridge (5), Cardiff (7), Coventry (3), Dundee (3), Edinburgh (7), Glasgow (10), Kilmarnock (1), Liverpool (4), Manchester (2), Newcastle (21), Norwich (1), London St Georges (3) and Sheffield (2).

\section{Procedures}

\section{Anti-thyroid drug regimen block and replace regimen (BR) or dose titration (DT)}

Patients were treated with ATD in a similar initial dose $(0.75 \mathrm{mg} / \mathrm{kg} /$ day of CBZ) prior to randomisation with the expectation that this ATD dose would abolish endogenous thyroid hormone production in the majority of patients. Patients in the BR arm received thyroid hormone in a replacement dose when the serum thyroid hormone concentrations fell below the upper limit of the local reference range, whilst patients randomised to DT underwent ATD dose reduction as they became euthyroid (FT4 levels within the local reference range). The guidelines provided to investigators have

This work is licensed under a Creative Commons Attribution-NonCommercial-NoDerivatives 4.0 International License.ifica.com at 04/26/2023 03:56:17AM 
been published (7), and the key components of the BR or DT regimen are included in Table 1 . Scheduled visits were at 1, 4, 8, 12, 16 and 26 weeks during the initial 6 months with thyroid function checked at each visit. Unscheduled visits (sometimes with associated thyroid function tests) could take place between these assessments as clinically indicated.

\section{Carbimazole and propylthiouracil ATD}

Paediatricians in the UK usually commence children with thyrotoxicosis on CBZ, and only three patients were treated with PTU prior to the 6-month visit; the first patient was commenced on PTU at visit 2, the second at visit 4 and the third at visit 5 . When patients were treated with PTU, a similar guideline was followed with the recommendation that $1 \mathrm{mg}$ of CBZ is equivalent to $10 \mathrm{mg}$ of PTU.

\section{Statistics}

Statistical analysis was performed using STATA SE 16.1 (StataCorp LLC, College Station, TX, USA). Baseline and 6-month Z-scores for height, weight and BMI were generated using 1990 British Growth Reference Data (8). Paired $t$-tests were used to compare mean change in Z-scores from baseline to 6 months, whilst unpaired $t$-tests were used to compare Z-scores between the two treatment regimens. We used two measures of biochemical control; the time taken after commencing ATD treatment for serum TSH to no longer be suppressed (defined as a TSH concentration that was no longer below the local TSH assay detection threshold) and time for serum FT4 to fall below the upper end of the local laboratory reference range for FT4. A cut-off time of 184 days (6 months) was used, with any patient who had not normalised by that point, being rightcensored. Kaplan-Meier curves enabled the time taken for $50 \%$ of participants to achieve a non-suppressed TSH or normal FT4 within the local age-related reference range in each group to be determined. Log-rank tests were used to compare the likelihood of the TSH/FT4 values normalising within the first 6 months, testing the null hypothesis that there was no difference in biochemical control in BR and DT regimens.

\section{Ethics}

The trial was registered as EudraCT Number: 2011-00123840 (DDX ref: MF8000/13328) and as NCT01436994 on Clinicaltrials.gov. A favourable ethical committee opinion was received in 2004 (Berkshire Research Ethics Committee, UK).

\section{Results}

\section{Baseline characteristics}

Data were available in 80 patients (baseline) and 78 patients (61 females) at 6 months after two patients withdrew (reluctance to attend study visits and take medication as prescribed). Of the 78 patients, 39 were allocated to BR and 39 to DT. Mean age at presentation was 12.7 years (S.D. 3.0, range 3.3-16.9 years; see Table 2); $42.5 \%$ (34/80) of patients reported having either a first- or second-degree relative with autoimmune thyroid disease.

Thyrotropin receptor antibody (TRAb) titres were not measured in all centres but when assayed were positive in 44 of 48 cases confirming Graves' disease as the key cause of thyroid hormone excess. Mean height and weight Z-score

Table 1 Instructions for initial anti-thyroid drug (ATD) treatment. The primary objective of both regimens was to maintain FT4 concentrations in the normal laboratory range with a TSH that is also within the normal laboratory range (neither elevated nor suppressed). Propylthiouracil (PTU) was used on the basis that $1 \mathrm{mg}$ of carbimazole (CBZ) is approximately equivalent to $10 \mathrm{mg}$ of PTU.

\section{Block and replace regimen}

- $\quad$ Start CBZ at $0.75 \mathrm{mg} / \mathrm{kg} /$ day

- Consider increasing CBZ to $1 \mathrm{mg} / \mathrm{kg} /$ day if FT4 remains above normal range with suppressed TSH after 2 months (and consider compliance)

- When FT4 levels are in the lower half of the local reference range or below, start thyroxine in a low replacement dose $\sim 75$. $\mu \mathrm{g} / \mathrm{m}^{2}$ (even if TSH suppressed during first 4 months)

- If compliance is not a concern and if the thyroxine dose is not * greater than $75 \mu \mathrm{g} / \mathrm{m}^{2}$, then a suppressed TSH beyond the first 4 months of therapy should be managed by increasing the dose of ATD in the first instance.

- The treatment regimen may not require adjustment if the FT4 is relatively high but the TSH is normal.

\section{Dose titration regimen}

- Start CBZ at $0.75 \mathrm{mg} / \mathrm{kg} /$ day

When FT4 levels fall into normal range, reduce dose to 0.25 $\mathrm{mg} / \mathrm{kg} /$ day with aim of keeping T4 and TSH within the normal range. Be primarily guided by T4 value (not TSH) in first 4 months after diagnosis.

If the patient is hypothyroid, then reduce carbimazole dose by $5 \mathrm{mg} / \mathrm{day}$ if $<30 \mathrm{~kg}$ or $10 \mathrm{mg}$ if $>30 \mathrm{~kg}$

After the first 4 months be guided by both the TSH and free T4; if the TSH is suppressed in the presence of normal free T4 values, consider increasing the dose of CBZ as above.

- The treatment regimen may not require adjustment if the FT4 is relatively high but the TSH is normal.
This work is licensed under a Creative Commons Attribution-NonCommercial-NoDerivatives 4.0 International License.ifica.com at 04/26/2023 03:56:17AM 
Table 2 Baseline, 6-month and 3-year demographic and clinical characteristics in young people with thyrotoxicosis.

\begin{tabular}{|c|c|c|c|}
\hline Baseline & Overall & $\begin{array}{l}\text { Block and } \\
\text { replace }\end{array}$ & Dose titration \\
\hline characteristics & Mean (S.D.) & Mean (S.D.) & Mean (S.D.) \\
\hline Age (years) $(n=80)$ & $12.7(3.0)$ & $12.9(2.6)$ & $12.5(3.4)$ \\
\hline Height $(\mathrm{cm})$ & $156.1(17.0)$ & $157.3(15.4)$ & $153.9(19.4)$ \\
\hline Height Z-score & $0.48(1.5)$ & $0.48(1.4)$ & $0.48(1.5)$ \\
\hline Weight (kg) & $46.9(14.2)$ & $47.0(13.6)$ & $46.3(15.3)$ \\
\hline Weight Z-score & $0.31(1.0)$ & $0.26(1.0)$ & $0.37(0.9)$ \\
\hline $\mathrm{BMI}\left(\mathrm{kg} / \mathrm{m}^{2}\right)$ & $18.8(3.0)$ & $18.6(3.0)$ & $18.9(3.1)$ \\
\hline BMI Z-score $\left(\mathrm{kg} / \mathrm{m}^{2}\right)$ & $0.10(1.0)$ & $-0.02(1.0)$ & $0.19(0.94)$ \\
\hline $\begin{array}{l}\text { 6-month } \\
\text { characteristics }\end{array}$ & Mean (S.D.) & Mean (S.D.) & Mean (S.D.) \\
\hline Age (years) $(n=78)$ & $13.1(3.0)$ & $13.2(2.6)$ & $12.9(3.5)$ \\
\hline Height $(\mathrm{cm})$ & $157.0(17.3)$ & $158.5(15.2)$ & $155.7(19.0)$ \\
\hline Height Z-score & $0.39(1.5)$ & $0.43(1.5)$ & $0.36(1.6)$ \\
\hline Weight (kg) & $52.7(16.0)$ & $52.6(15.3)$ & $52.7(16.9)$ \\
\hline Weight Z-score & $0.78(1.0)$ & $0.68(1.1)$ & $0.89(0.9)$ \\
\hline $\mathrm{BMI}\left(\mathrm{kg} / \mathrm{m}^{2}\right)$ & $20.9(3.7)$ & $20.5(3.5)$ & $21.2(3.8)$ \\
\hline BMI Z-score $\left(\mathrm{kg} / \mathrm{m}^{2}\right)$ & $0.81(0.97)$ & $0.68(0.95)$ & $0.93(0.99)$ \\
\hline $\begin{array}{l}\text { 3-year } \\
\text { characteristics }\end{array}$ & Mean (S.D.) & Mean (S.D.) & Mean (S.D.) \\
\hline Age (years) $(n=62)$ & $15.5(3.2)$ & $15.8(2.8)$ & $15.2(3.6)$ \\
\hline Height $(\mathrm{cm})$ & $162.0(15.6)$ & $163.0(13.6)$ & $161.0(17.5)$ \\
\hline Height Z-score & $0.26(1.3)$ & $0.18(1.1)$ & $0.34(1.4)$ \\
\hline Weight (kg) & $58.0(15.1)$ & 57.8 (13.7) & $58.2(16.6)$ \\
\hline Weight Z-score & $0.51(1.1)$ & $0.33(1.0)$ & $0.67(1.1)$ \\
\hline $\mathrm{BMI}\left(\mathrm{kg} / \mathrm{m}^{2}\right)$ & $21.7(3.8)$ & $21.6(3.7)$ & $21.8(3.9)$ \\
\hline BMI Z-score $\left(\mathrm{kg} / \mathrm{m}^{2}\right)$ & $0.49(1.1)$ & $0.36(1.1)$ & $0.62(1.1)$ \\
\hline
\end{tabular}

at presentation were 0.48 (S.D. 1.5) and 0.31 (S.D. 1.0) respectively, with a mean BMI Z-score of 0.10 (s.D. 1.0).

\section{Eye disease}

Eye disease status was graded by the treating clinician at baseline visit, with information available for 77 of 80 (96.2\%) patients; 43 of 80 (53.8\%) patients were reported to have no signs of thyroid eye disease and 34 of 80 (42.5\%) patients were said to have mild signs including lid retraction, stare and mild proptosis. No patient had severe orbitopathy at presentation (defined as proptosis $>22 \mathrm{~mm} /$ extraocular muscle involvement/corneal involvement/ visual disturbance).

\section{ATD dose (carbimazole)}

The mean daily dose of carbimazole in the BR group during the first 6 months was $0.9 \mathrm{mg} / \mathrm{kg}$ compared to $0.5 \mathrm{mg} / \mathrm{kg}$ in the DT group (95\% CI for difference $0.1,0.8 ; P<0.010$ ). Five patients were commenced on PTU at a mean daily dose of $2.8 \mathrm{mg} / \mathrm{kg}$. The maximum dose of carbimazole prescribed was $60 \mathrm{mg}$ in three patients, which was equivalent to 0.68 , 0.73 and $0.78 \mathrm{mg} / \mathrm{kg}$.

\section{Growth and physique}

In the full cohort, mean height Z-score reduced from 0.48 (S.D. 1.5) at baseline to 0.39 (S.D. 1.5) at 6 months (95\% CI for difference $(-0.06,-0.26) ; P=0.002)$ while mean weight Z-score increased from 0.31 (S.D. 1.0) to 0.78 (S.D. 1.0, 95\% CI for difference $(0.34,0.53) ; P<0.001)$ and mean BMI Z-score increased from 0.10 (S.D. 1.0) to 0.81 (S.D. $0.97,95 \% \mathrm{CI}$ for difference $(0.57,0.86) ; P<0.001)$. One individual gained $15.4 \mathrm{~kg}$ in weight, and 12 other subjects gained more than $10 \mathrm{~kg}$ in the 6-month period (Fig. 1 and Table 2). These parameters were not statistically significantly different when BR and DT groups were compared. The increase in BMI Z-score was greater in those with a FT4 $>50 \mathrm{pmol} / \mathrm{L}$ at randomisation when compared to those with an initial T4 of $<50 \mathrm{pmol} / \mathrm{L}$ (0.93 vs 0.53 ; $95 \%$ CI for difference $0.11,0.68, P=0.007)$. Bone age was measured in 28 of 80 (35.0\%) patients and demonstrated that most patients had an advanced bone age in keeping with the fact that patients were relatively tall (Fig. 2).

\section{Biochemistry}

\section{TSH}

At baseline, 39 of 40 patients in each group had a suppressed $\mathrm{TSH}$ concentration $(<0.05 \mathrm{mU} / \mathrm{L})$. The log-rank test indicated that there was no significant difference between

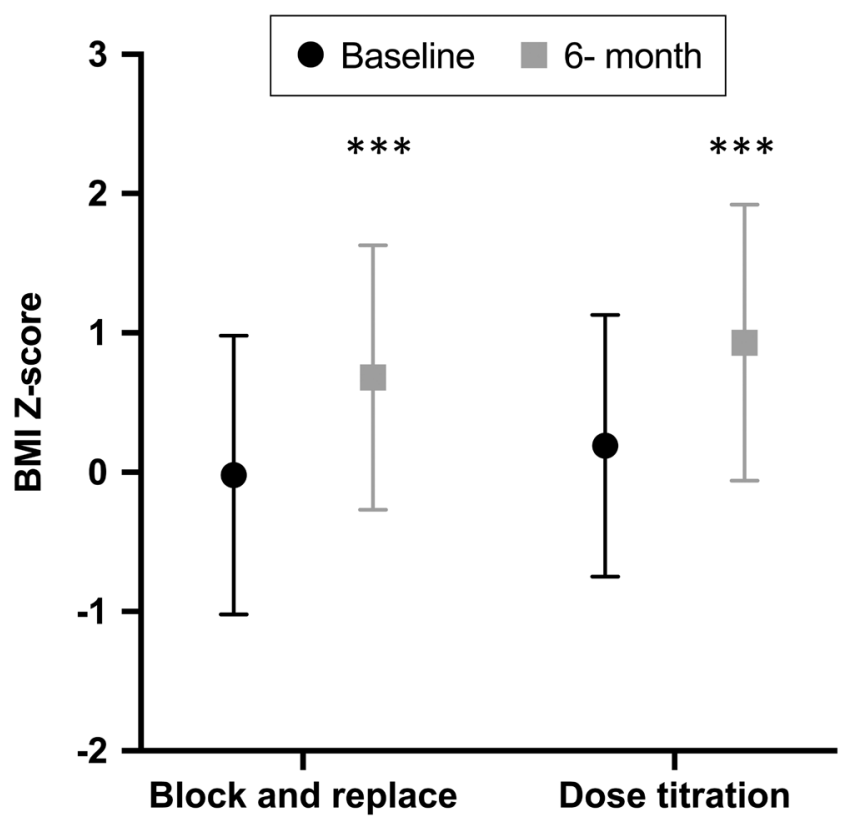

Figure 1

BMI Z-scores at baseline and 6 months after ATD treatment in young people with thyrotoxicosis randomised to block and replace or dose titration. Data presented are mean (symbol) and s.D. (whiskers). $\star \star \star$ Signifies $P<0.001$ for difference between baseline and 6-month data.

This work is licensed under a Creative Commons Attribution-NonCommercial-NoDerivatives 4.0 International License.ifica.com at 04/26/2023 03:56:17AM 


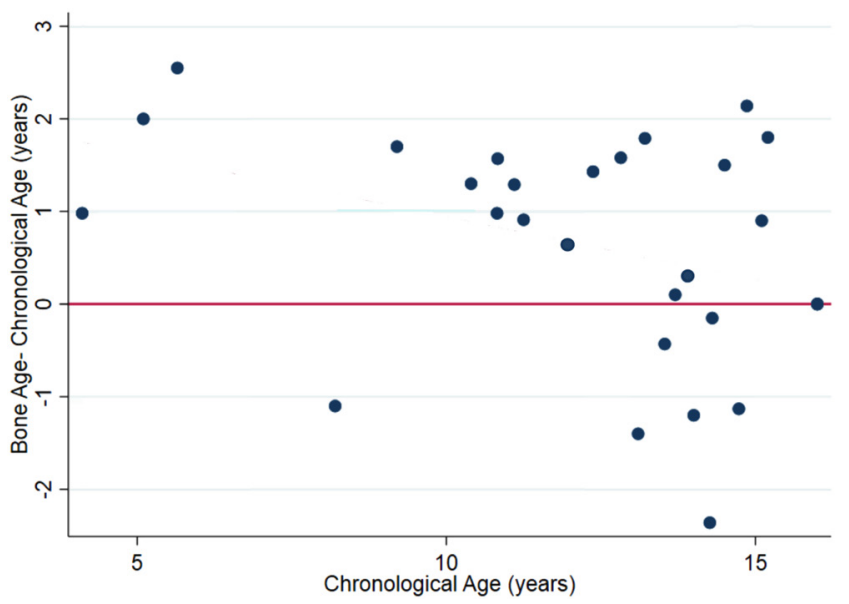

Figure 2

Difference between bone age and chronological age vs chronological age in trial patients at baseline; a positive difference indicates that bone age is greater than chronological age.

the two groups in the time taken for patients to achieve non-suppressed TSH concentrations $(P=0.273)$ during the 6 months of treatment; 16 patients in the BR group and 11 in the DT group still had low TSH concentration at 6 months (Fig. 3). The time taken for $50 \%$ of patients to no longer have a suppressed TSH was 154 days in the BR group (95\% CI 95, 184), compared to 111 days in the DT group, (95\% CI 84, 175). Post hoc analysis showed that patients who still had a suppressed TSH by 6 months had higher mean baseline FT4 levels (72.7 vs 51.7 pmol/L; 95\% CI for difference $1.73,31.7, P$ value for difference $=0.029$ ).

\section{Free T4}

At baseline, 36 patients (90\%) in each group had an elevated FT4 concentration. This reflects the fact that patients were treated with ATD from diagnosis and then randomised to BR/DT. Mean FT4 concentrations at baseline were 57.5 $\mathrm{pmol} / \mathrm{L}$ in $\mathrm{BR}$ and $58.4 \mathrm{pmol} / \mathrm{L}$ in DT. The log-rank test indicated that the time taken to achieve FT4 levels within reference range was reduced in the DT group when compared to the BR group ( $P=0.049$; Fig. 4). There were 33 events (FT4 normalisations) in the BR group vs 41 expected compared to 35 events in the DT group when 27 were expected (see Fig. 4). The time taken for $50 \%$ of patients to have a FT4 within reference range was 28 days in the DT group $(95 \%$ CI 25,32$)$ compared to 35 days in the BR group ( $95 \%$ CI 28,58$)$.

\section{Discussion}

We describe the initial response to ATD therapy in a cohort of newly diagnosed young people with thyrotoxicosis treated with either a BR or DT ATD strategy.
TSH concentrations remained suppressed at 6 months post-diagnosis in approximately one-third of patients with no difference between the randomised treatment groups.

This study did not, in contrast to some earlier reports, indicate improved control when using the BR strategy (9). Thyroid hormone levels remained elevated for longer in the BR group despite the fact that a larger dose of ATD was administered although the difference between 50\% of patients achieving a normal FT4 in the two groups was 7 days, and we suspect that this is unlikely to be of major clinical significance in most patients. By 6 months, there were eight more patients than expected in the DT group who had normalised FT4 levels. We did not find differences in baseline characteristics that could account for this observation, and this could potentially indicate that medication concordance was better in the DT group on account of having to take fewer tablets. Alternatively, the addition of levothyroxine by clinicians at a relatively early stage in BR patients - contrary to protocol guidance - to reduce the likelihood of hypothyroidism could be a factor. The protocol advised clinicians to add levothyroxine only when circulating levels were within the normal reference range, but levothyroxine was added in four patients when T4 levels were still elevated. We suspect that the early introduction of thyroxine was to ensure that patients did not become hypothyroid prior to the next clinic visit that was typically in 4 weeks' time. A sensitivity analysis with these patients excluded continued to show a small difference of marginal statistical and clinical significance (data not shown). Data on FT3 concentrations were not collected in this trial, but it is also possible that a more rapid reduction in FT3 levels - in units where this was measured - led to an earlier introduction of levothyroxine in BR patients. A further potential explanation for the difference observed is the fact that TSH normalisation can be associated with a relatively high FT4 in some young people with primary hypothyroidism $(10,11)$ because thyroid hormone replacement usually involves $\mathrm{T} 4$ administration alone whilst the thyroid gland manufactures both $\mathrm{T} 4$ and biologically active T3. The likelihood of a high FT4 in the BR group would therefore be increased if endogenous thyroid hormone production (including T3) is abolished in BR but not to the same extent in DT where the dose of ATD is smaller and hence T3 production is ongoing. Equivalent tissue $\mathrm{T} 3$ generation may then require higher circulating FT4 levels in BR patients who are fully 'blocked'. A similar pattern has recently been observed in a study of adults treated with BR or DT (12). Finally, the titre of TRAb has also been shown to be related to TSH suppression with stimulating antibodies having the potential to suppress

This work is licensed under a Creative Commons Attribution-NonCommercial-NoDerivatives 4.0 International License ifica.com at 04/26/2023 03:56:17AM 


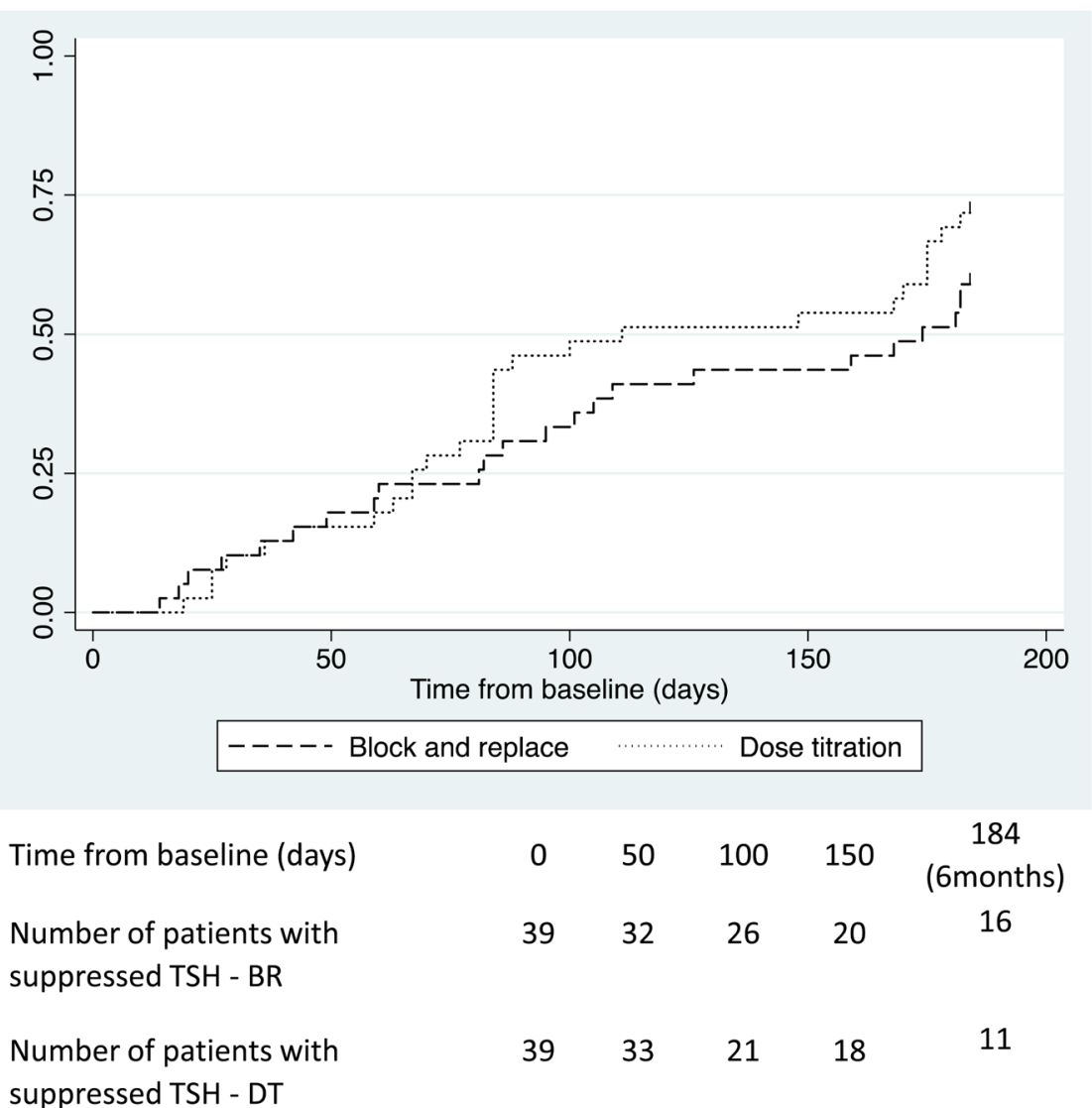

\section{Figure 3}

Kaplan-Meier curves illustrating the time taken for young people with thyrotoxicosis randomised to either a block and replace or dose titration regimen to first achieve non-suppressed TSH levels in the initial 6 months of ATD treatment.
TSH levels (13). Whilst differences in antibody titre may therefore impact on thyroid function tests and their interpretation, ours was a randomised trial and so there is no reason to suspect that there were differences in TRAb titre between BR and DT groups.

This study has confirmed the importance of using thyroid hormone concentrations as the major guide when adjusting treatment for up to 6 months or more postdiagnosis rather than TSH because of the lengthy period of TSH suppression observed after diagnosis.

The fact that patients with thyrotoxicosis are at risk of weight gain following treatment has been highlighted before $(4,5,6)$, and we have shown that this is a significant problem for some young people in the first months of therapy on both BR and DT treatment and that weight gain was greatest in those with the more profound thyroid dysfunction at presentation. Whilst weight gain might be attributed to growth in these young people, increases in BMI Z-score suggest a substantial impact of initial treatment on fat mass. Similar changes in weight have previously been observed in treatment of adults with hyperthyroidism, with the greatest weight gains seen in those rendered temporarily hypothyroid as a result of treatment (14). We speculate that this pattern reflects a reduction in calorie requirement, not matched by a similar reduction in satiety. This may have significant implications for concordance and should be discussed at the start of treatment.

We have confirmed that eye signs are relatively common in young people with thyrotoxicosis but that severe orbitopathy is rare. The figures that we have identified are similar to those previously reported (15) although it should be noted that the data were collected by paediatricians rather than ophthalmologists, and we cannot easily make the distinction between individuals with hyper adrenergic activity rather than true thyroid eye disease. The bone age data were derived from a relatively small subgroup but suggests that there may be a degree of bone age advancement in the younger child in keeping with relatively rapid growth and associated tall size.

We suspect that medication compliance was not optimal in all subjects in this 'real-world' study, and it is known that many patients with chronic illness do not follow treatment advice (16). However, we do not think that all patients with a suppressed TSH at 6 months were poorly compliant because many had normal thyroid hormone concentrations by this stage.

This trial has a number of limitations including the fact that TRAb analysis was not conducted in all patients 


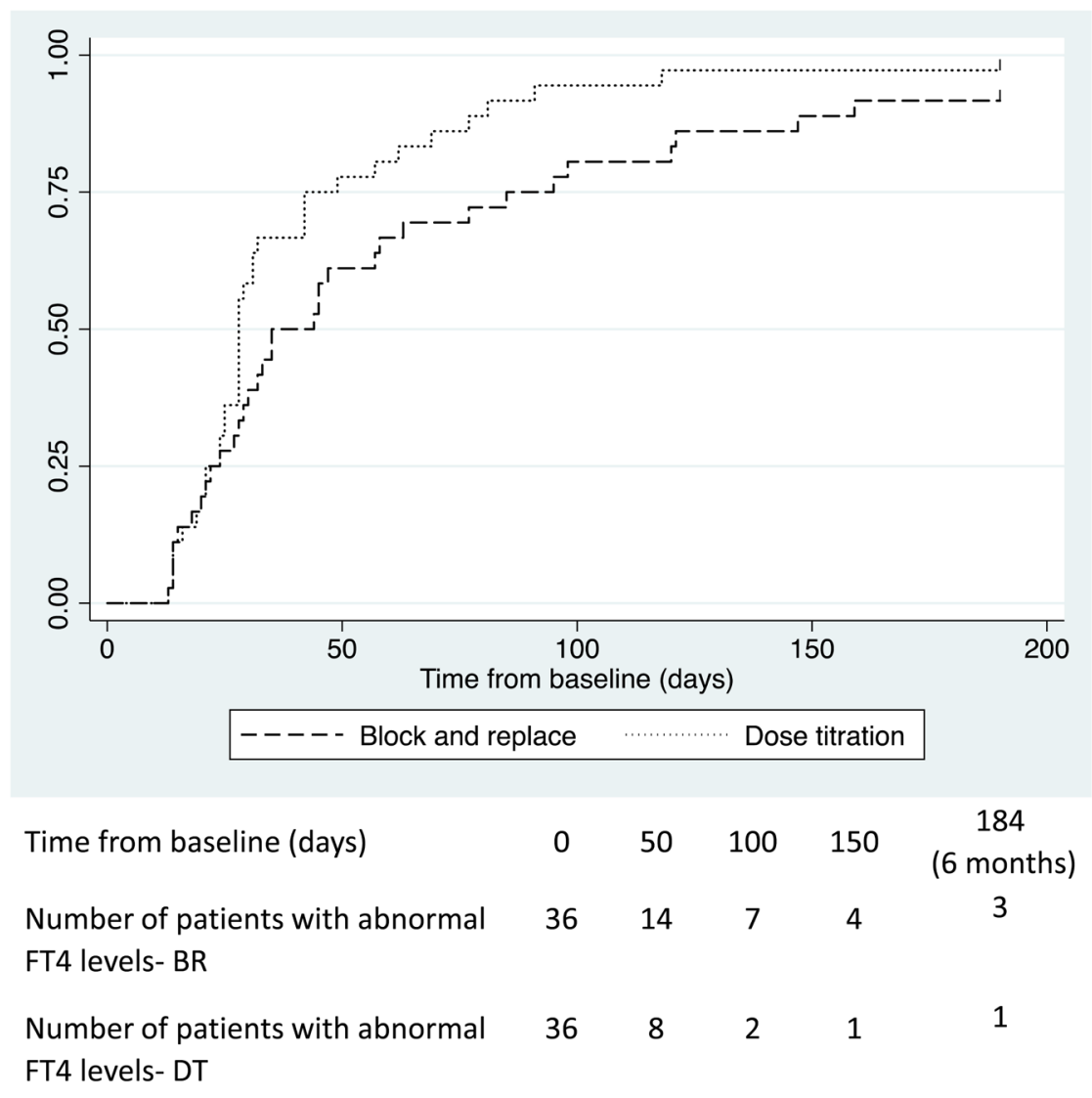

\section{Figure 4}

Kaplan-Meier curves illustrating time taken for young people with thyrotoxicosis randomised to either a block and replace or dose titration regimen to first achieve normal FT4 levels in the initial 6 months of ATD treatment. because not all units could access a pertinent assay (7). However, it should be noted that patients were recruited by paediatric endocrinologists who will be aware of the spectrum of thyroid dysfunction and when TRAb were measured they were positive in $92 \%$ of participants. We therefore suspect that the number of patients with selflimiting thyroiditis was small. A further limitation of the trial is that the endpoint used was FT4 concentrations and not FT3. This was because not all centres were routinely analysing FT3 concentrations at the time of the trial. Serum FT3 is a more sensitive indicator of a hyperthyroid state in Graves' disease (17), and some of the alterations in ATD dose may reflect local FT3 concentrations that were measured but not reported in the trial.

In summary, when children are managed according to the BR/DT protocols described in this study, patients appear to normalise FT4 concentrations more rapidly with DT. There are a number of potential explanations for this, but it is unclear to what extent this observation is clinically relevant. A more detailed assessment of clinical parameters in patients managed with BR and DT regimens would be required to comment further, but these data support rather than refute existing guidance recommending DT rather than BR (3). About $90 \%$ of patients managed with ATD can expect normal thyroid hormone concentrations by 6 months, although TSH concentrations can remain suppressed for some time. Excessive weight gain is a concern in some patients irrespective of the underlying treatment regimen (BR or DT).

\section{Declaration of interest}

T C and S P were members of the NICE Thyroid Guideline Committee 2019. The other authors have nothing to disclose.

\section{Funding}

This trial was funded by both the British Thyroid Foundation and by the Child Growth Foundation. C W was funded by the Medical Research Council/MDUK (MR/N020588/1).

\section{Author contribution statement}

T C conceived and designed the study with input from MD, DBD and SHSP. C L W, N W, M C, R W and S H S P were involved in data collection and data analysis. The manuscript was written primarily by $T C$ and $C L W$ with substantial input from MC and SHSP. The other authors reviewed the MS prior to submission. Members of the BSPED were involved in patient recruitment and assessment as well as data submission. 


\section{Acknowledgments}

The author would like thank the patients who participated in the trial. The author would also like to acknowledge the input of members of the BSPED study team including Amelia Mayo, Craig Oxley (Aberdeen), Jeremy Kirk, Tim Barrett (Birmingham), Carlo Acerini (Cambridge); John Gregory, Justin Warner (Cardiff); Heather Stirling (Coventry); Stephen Greene (Dundee); Amanda Drake (Edinburgh); Guftar Shaikh, Emma-Jane Gault (Glasgow); Jon Staines (Kilmarnock); Joanne Blair and Poonam Dharmaraj (Liverpool); Indi Banerjee, Sarah Ehtisham (Manchester); Helen Johnstone, Debbie Matthews, Kate Owen (Newcastle); Nandu Thalange (Norwich); Paul Dimitri, Neil Wright, Jerry Wales (Sheffield); Assunta Albanese, Murray Bain (St.Georges) as well as the specialist nurse teams who were involved in the process of supporting patients and collecting data. We would also like to acknowledge the support of Cambridge and Newcastle clinical trials units as well as Stephen Bruce, Neil Davidson, Julie Edge, Eve Smith and the members of the steering and data monitoring committees.

\section{References}

1 Williamson S \& Greene SA. Incidence of thyrotoxicosis in childhood: a national population based study in the UK and Ireland. Clinical Endocrinology 201072 358-363. (https://doi.org/10.111 1/j.1365-2265.2009.03717)

2 Havgaard Kjær R, Smedegård Andersen M \& Hansen D. Increasing incidence of juvenile thyrotoxicosis in Denmark: a nationwide study, 1998-2012. Hormone Research in Paediatrics 201584 102-107. (https:// doi.org/10.1159/000430985)

3 Ross DS, Burch HB, Cooper DS, Greenlee MC, Laurberg P, Maia AL, Rivkees SA, Samuels M, Sosa JA, Stan MN, et al. 2016 American Thyroid Association guidelines for diagnosis and management of hyperthyroidism and other causes of thyrotoxicosis. Thyroid 201626 1343-1421. (https://doi.org/10.1089/thy.2016.0229)

4 Van Veenendaal NR \& Rivkees SA. Treatment of pediatric Graves' disease is associated with excessive weight gain. Journal of Clinical Endocrinology and Metabolism 201196 3257-3263. (https://doi. org/10.1210/jc.2011-1601)

5 Kyriacou A, Kyriacou A, Makris KC, Syed AA \& Perros P. Weight gain following treatment of hyperthyroidism - a forgotten tale. Clinical Obesity 20199 e12328. (https://doi.org/10.1111/cob.12328)

6 Alonso GT, Rabon S \& White PC. Weight gain after treatment of Graves' disease in children. Clinical Endocrinology 2018 88 66-70. (https://doi.org/10.1111/cen.13493)

7 Wood CL, Cole M, Donaldson M, Dunger DB, Wood R, Morrison N, Matthews JNS, Pearce SHS \& Cheetham TD. Randomised trial of block and replace vs dose titration thionamide in young people with thyrotoxicosis. European Journal of Endocrinology 2020183 637-645. (https://doi.org/10.1530/EJE-20-0617)

8 Cole TJ, Freeman JV \& Preece MA. British 1990 growth reference centiles for weight, height, body mass index and head circumference fitted by maximum penalized likelihood. Statistics in Medicine 199817 407-429.

9 Vigone MC, Peroni E, Di Frenna M, Mora S, Barera G \& Weber G. 'Block-and-replace' treatment in Graves' disease: experience in a cohort of pediatric patients. Journal of Endocrinological Investigation 202043 595-600. (https://doi.org/10.1007/s40618-019-01144-0)

10 Kempers MJE, Van Trotsenburg ASP, Van Tijn DA, Bakker E, Wiedijk BM, Endert E, de Vijlder JJ \& Vulsma T. Disturbance of the fetal thyroid hormone state has long-term consequences for treatment of thyroidal and central congenital hypothyroidism. Journal of Clinical Endocrinology and Metabolism 200590 4094-4100. (https://doi. org/10.1210/jc.2005-0197)

11 Fish LH, Schwartz HL, Cavanaugh J, Steffes MW, Bantle JP \& Oppenheimer JH. Replacement dose, metabolism, and bioavailability of levothyroxine in the treatment of hypothyroidism. Role of triiodothyronine in pituitary feedback in humans. New England Journal of Medicine 1987316 764-770. (https://doi.org/10.1056/ NEJM198703263161302)

12 Žarković M, Wiersinga W, Perros P, Bartalena L, Donati S, Okosieme O, Morris D, Fichter N, Lareida J, Daumerie C, et al. Antithyroid drugs in Graves' hyperthyroidism: differences between 'block and replace' and 'titration' regimes in frequency of euthyroidism and Graves' orbitopathy during treatment. Journal of Endocrinological Investigation 202144 371-378. (https://doi.org/10.1007/s40618-020-01320-7)

13 Brokken LJS, Wiersinga WM \& Prummel MF. Thyrotropin receptor autoantibodies are associated with continued thyrotropin suppression in treated euthyroid Graves' disease patients. Journal of Clinical Endocrinology and Metabolism 200388 4135-4138. (https://doi. org/10.1210/jc.2003-030430)

14 Dale J, Daykin J, Holder R, Sheppard MC \& Franklyn JA. Weight gain following treatment of hyperthyroidism. Clinical Endocrinology 2001 55 233-239. (https://doi.org/10.1046/j.1365-2265.2001.01329.x)

15 Szczapa-Jagustyn J, Gotz-Więckowska A \& Kocięcki J. An update on thyroid-associated ophthalmopathy in children and adolescents. Journal of Pediatric Endocrinology and Metabolism 201629 1115-1122. (https://doi.org/10.1515/ipem-2016-0122)

16 Kandukuri RC, Khan MA \& Soltys SM. Nonadherence to medication in hypothyroidism: a case report. Primary Care Companion to the Journal of Clinical Psychiatry 201012 PCC.09m00863. (https://doi.org/10.4088/ PCC.09m00863gre)

17 Harvengt J, Boizeau P, Chevenne D, Zenaty D, Paulsen A, Simon D, Guilmin Crepon S, Alberti C, Carel JC \& Léger J. Triiodothyroninepredominant Graves' disease in childhood: detection and therapeutic implications. European Journal of Endocrinology 2015172 715-723. (https://doi.org/10.1530/EJE-14-0959)

Received in final form 29 September 2021

Accepted 25 October 2021

Accepted Manuscript published online 25 October 2021 https://etj.bioscientifica.com https://doi.org/10.1530/ETJ-21-0043 (c) 2022 The authors Published by Bioscientifica Ltd.
This work is licensed under a Creative Commons Attribution-NonCommercial-NoDerivatives 4.0 International License.ifica.com at 04/26/2023 03:56:17AM 